\section{Comparative study of 27-gauge vs 25-gauge vitrectomy for epiretinal membrane}

K Mitsui, J Kogo, H Takeda, A Shiono, H Sasaki, Y Munemasa, Y Kitaoka and H Takagi
Department of

Ophthalmology, St

Marianna University School of Medicine, Kawasaki,

Kanagawa, Japan

Correspondence:

J Kogo, Department of Ophthalmology, St Marianna University School of Medicine, 2-16-1 Sugao, Miyamae-ku, Kawasaki, Kanagawa 215-8511, Japan Tel: +81 44977 8111; Fax: +8144976 7435

E-mail:kogo@marianna-u.ac.jp

Received: 18 August 2015 Accepted in revised form: 10 November 2015

Published online:

8 January 2016

\begin{abstract}
Purpose The purpose of this study was to compare 27-gauge (27G) with 25-gauge (25G) microincision vitrectomy in patients with epiretinal membrane (ERM).

Participants Seventy-four eyes of 66 patients undergoing 3-port pars plana vitrectomy using $27 \mathrm{G}$ or $25 \mathrm{G}$ instrumentation. Methods Seventy-four eyes of 66 patients with ERM, who underwent $27 \mathrm{G}$ or $25 \mathrm{G}$ microincision vitrectomy were prospectively evaluated.

Results The mean operation time for vitrectomy was significantly longer in the $27 \mathrm{G}$ group than in the $25 \mathrm{G}$ group $(9.9 \pm 3.5$ vs $6.2 \pm 2.7 \mathrm{~min}$, respectively, $P<0.0001$ ). No statistically significant difference was found between the two groups in terms of the mean operation time for ERM-inner limiting membrane peeling (27G vs 25G: $20.2 \pm 9.9$ vs $16.1 \pm 9.3 \mathrm{~min}, P=0.14$ ), although the time for vitreous cutting was longer in the $27 \mathrm{G}$ group $(9.9 \pm 3.5$ vs $6.2 \pm 2.7 \mathrm{~min}$, respectively, $P<0.0001$ ). The flare value, intraocular pressure (IOP), and rate of hypotony 1 day after surgery did not differ between the $27 \mathrm{G}$ and $25 \mathrm{G}$ groups (flare value: 18.7 vs 17.2; IOP: 8.8 vs $9.7 \mathrm{~mm} \mathrm{Hg}$; rate of hypotony: 30 vs $35 \%$, respectively). There was no significant difference in the surgically induced astigmatism between the two groups in the follow-up period. The mean time required for wound closure did not show a significant difference between the $27 \mathrm{G}$ and $25 \mathrm{G}$ groups ( 7.7 vs 8.6 weeks, respectively).

Conclusion The $27 \mathrm{G}$ system is as safe and useful for ERM vitrectomy as the 25G system. Based on its potential, further improvement of $27 \mathrm{G}$ instruments could result in greater efficiency.

Eye (2016) 30, 538-544; doi:10.1038/eye.2015.275; published online 8 January 2016
\end{abstract}

\section{Introduction}

The introduction of transconjunctival microincision vitrectomy surgery (MIVS) with 25 - or 23-gauge (25G or 23G) instrumentation has resulted in low rates of intraoperative and postoperative complications such as early postoperative hypotony and endophthalmitis. ${ }^{1-4}$ Faster wound-healing, decreased operation time, improved patient comfort, and less postoperative inflammation with early visual recovery have been reported. ${ }^{4-7}$ Although these improvements make surgery safer, patient care and treatment compliance remain the main targets of technological research. In recent times, a 27G instrument system has been introduced. Oshima $e a^{8}{ }^{8}$ reported that no eyes developed wound-sealing-related complications such as subconjunctival air bubbles or hypotony from postoperative day 1 when using the $27 \mathrm{G}$ system.

To the best of our knowledge, the efficacy of the $27 \mathrm{G}$ system has not been evaluated in a randomized, prospective manner and compared with the $25 \mathrm{G}$ system. To evaluate the feasibility, safety, and efficiency of a $27 \mathrm{G}$ instrument system for MIVS, we performed a randomized, comparative, prospective study of the surgical results of $27 \mathrm{G}$ and $25 \mathrm{G}$ vitrectomy limited to idiopathic epiretinal membrane (ERM).

Patients and methods

We prospectively studied 74 eyes of 66 patients with an ERM treated with $27 \mathrm{G}$ or $25 \mathrm{G}$ transconjunctival sutureless vitrectomy (TSV) at the St Marianna University School of Medicine Hospital between May 2013 and September 2014. This study was approved by the Institutional Review Committee of St Marianna University School of Medicine and written informed consent for participation was obtained from all patients. We registered this study in the 
University Hospital Medical Information Network (UMIN ID:000017847). The authors confirm that all ongoing and related trials for this drug/intervention are registered. All patients were followed up for at least 6 months postoperatively by 31 May 2015. The procedure used conformed to the tenets of the Declaration of Helsinki.

Thirty-seven eyes of 33 patients underwent 25G TSV using the Alcon Constellation Vision System (Alcon Laboratories, Inc., Forth Worth, TX, USA) including a three-port trocar cannula system (Total Plus Pak). This instrument continuously monitors the infusion rate and intraocular fluid dynamics, allowing true intraocular pressure (IOP) control during the entire surgery. The surgical parameters were 5000 cuts per minute (cpm) and a vacuum of 0-650 mm Hg. During surgery, IOP was controlled to $20 \mathrm{~mm} \mathrm{Hg}$. In addition, 37 eyes of 33 patients underwent 27G TSV using the Alcon Accurus Surgical System (Alcon Laboratories, Inc.). The surgical parameters were $1000-2500 \mathrm{cpm}$ and vacuum of 0-600 mm Hg. ${ }^{8}$ Sclerectomies were created with a DORC 27G system (DORC, Zuidland, The Netherlands).

Patients were excluded from the study if they had a history of prior scleral buckling and pars plana vitrectomy, high myopia with a refractive error of $>-8.00$ diopters (D), and severe cataract of higher than grade 3 . All surgeries were a randomization procedure. The eyes were randomly assigned to the $25 \mathrm{G}$ or $27 \mathrm{G}$ group in an alternating manner before surgery. If a patient had bilateral ERM, the first eye operated on was randomly assigned. All surgeries were performed by the same right-handed surgeon (HT). Finally, 37 eyes underwent 27G TSV surgery and 37 eyes underwent 25G TSV surgery.

The conjunctiva was displaced from the intended sclerotomy site and the trocar was placed at a $30^{\circ}$ oblique angle to the scleral surface $3.5-4.0 \mathrm{~mm}$ posterior to the limbus ${ }^{9}$ in both groups. The wound locations were superotemporal, superonasal, and inferotemporal as infusion sites in all eyes. If a significant cataract was present, combined cataract surgery was performed before the scleral incision for vitrectomy. All cataract surgeries were performed through a clear corneal 2.4-mm incision. At the end of the surgery, the cannulas were removed and moderate pressure was applied to the sclerotomy sites with a cotton-tipped applicator. After the removal of the infusion cannula, a balanced salt solution was injected if hypotony was found by tactile examination.

The IOP, aqueous flare value, and sclerotomy sites were examined prospectively at 1, 3, 7, 14, 30, 90, and 180 days after surgery. The postoperative IOP was measured with a Goldmann applanation tonometer. Hypotony was defined as an IOP $<7 \mathrm{~mm} \mathrm{Hg}$. The aqueous flare value was measured with noninvasive laser flare cell meter FC-500 (Kowa Company Ltd, Tokyo, Japan). The biomicroscopic and funduscopic findings and complications were also recorded. The duration of vitrectomy using the vitreous cutter was recorded as the operation time for vitrectomy and the duration of ERM and inner limiting membrane (ILM) peeling using vitreous forceps as the operation time for peeling.

The rate of surgically induced astigmatism (SIA) was calculated according to the report of Holladay et al $l^{10}$ Sclerotomy site images were recorded using a commercially available spectral domain optical coherence tomography (SD-OCT) apparatus (Cirrus HD-OCT, Carl Zeiss Meditec, Dublin, CA, USA) with a corneal adaptor module. Wound closure was defined as the absence of any scleral gap at the sclerotomy site in the anteriorsegment OCT (AS-OCT) images (Figure 1). All sclerotomies on the AS-OCT images were examined by three investigators (KM, JK, and HS). We evaluated the percentage of wound closure of all eyes in each group and the time required for wound closure in each sclerotomy during follow-up. Wound closure was defined as the closure of all three sclerotomies in each eye. Foveal macular thickness (FMT) was measured using the caliper function of the software package. Ophthalmic evaluations included best-corrected visual acuity (BCVA) and biomicroscopic and funduscopic findings at baseline and 1,3 , and 6 months postoperatively.

\section{Statistical analysis}

All statistical analyses were performed using StatView software (Abacus Concepts, Inc., Berkeley, CA, USA, 1992 ver.). Data correlations between final BCVA and SD-OCT characteristics or clinical features were investigated using the Spearman rank-correlation test. The Mann-Whitney
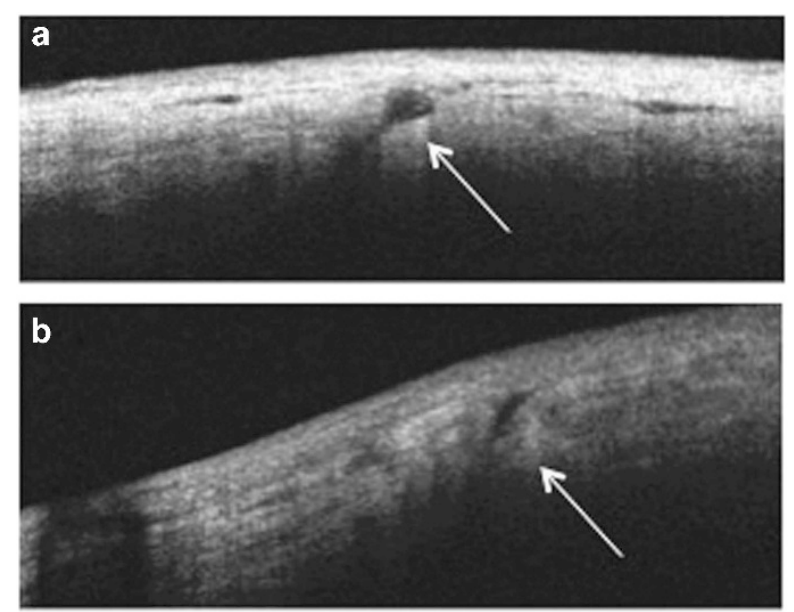

Figure 1 Anterior segment optical coherence tomography images of sclerotomies in 27G group. (a) Significant gap (arrow) in the sclera is visible as a hyporeflective area 1 day postoperatively. (b) Minimal gap (arrow) in the sclera is visible as a moderately hyporeflective area 14 days postoperatively. 
$U$-test and Wilcoxon signed-rank test were used for comparisons of the logarithm of the minimal angle of resolution (logMAR) BCVA, FMT, IOP, and aqueous flare between the two groups. $P$-values $<0.05$ were considered to represent statistically significant differences.

\section{Results}

Five patients in the $27 \mathrm{G}$ group and 1 patient in the $25 \mathrm{G}$ group dropped out during follow-up because of lost to visit hospital. Finally, 32 eyes in the $27 \mathrm{G}$ group and 36 eyes in the $25 \mathrm{G}$ group were evaluated (Table 1 ). There were no significant differences between the two groups in preoperative baseline characteristics, as shown in Table 1. The ERM and ILM were resected successfully in all cases. No intraoperative suture placement was necessary. Fluid-gas exchange was not performed in any eye. No choroidal detachment or bacterial endophthalmitis developed in either group. Cataract surgery combined with vitrectomy was performed in 53 eyes.

\section{Operation time}

The mean operation time for vitrectomy was significantly longer in the $27 \mathrm{G}$ group than in the $25 \mathrm{G}$ group $(9.9 \pm 3.5$ vs $6.2 \pm 2.7 \mathrm{~min}$, respectively, $P<0.0001)$. No statistically significant difference was found between the two groups in terms of the mean operation time for ERM-ILM peeling (27G vs 25G: $20.2 \pm 9.9$ vs $16.1 \pm 9.3 \mathrm{~min}, P=0.14$ ).

\section{Visual outcome}

The logMAR BCVA at 1, 3, and 6 months postoperatively improved significantly compared with that at baseline in each group (27G: $P=0.0345, P=0.0168$, and $P=0.0003$, respectively; 25G: $P=0.002, P=0.0053$, and $P=0.001$, respectively). There was no significant difference in logMAR BCVA between the two groups at each

Table 1 Baseline patient characteristics

\begin{tabular}{lccc}
\hline & $27 G$ & $25 G$ & P-value \\
\hline No. of eyes & 32 & 36 & 0.42 \\
Age (years) & $68.9 \pm 5.3$ & $65.4 \pm 11.4$ & 0.33 \\
Axial length (mm) & $23.9 \pm 1.3$ & $24.2 \pm 1.7$ & 0.69 \\
FMT ( $\mu$ m) & $397.2 \pm 98.1$ & $412.3 \pm 84.3$ & 0.25 \\
logMAR BCVA & $0.13 \pm 0.19$ & $0.27 \pm 0.3$ & 0.07 \\
Aqueous flare (photon/ms) & $5.3 \pm 1.8$ & $5.0 \pm 1.3$ & 0.56 \\
IOP (mm Hg) & $12.7 \pm 2.5$ & $12.2 \pm 1.9$ & 0.55 \\
Combined cataract surgery $(\%)$ & $28(84)$ & $25(69)$ & 0.15 \\
\hline
\end{tabular}

Abbreviations: BCVA, best-corrected visual acuity; ERM, epiretinal membrane; FMT, foveal macular thickness; ILM, internal limiting membrane; IOP, intraocular pressure; logMAR, logarithm of the minimal angle of resolution.

*Mann-Whitney $U$-test. follow-up visit ( 1 month: $P=0.13$; 3 months: $P=0.10$; 6 months: $P=0.06$, respectively; Figure $2 \mathrm{a})$.

\section{Time-course change in FMT}

In the 27G group, the mean FMT at 6 months postoperatively improved significantly compared with that at baseline $(P=0.0003)$. In the $25 \mathrm{G}$ group, the mean FMT at 3 and 6 months postoperatively improved significantly compared with that at baseline $(P=0.0004$ and $P<0.0001$, respectively). There was no significant difference in FMT between the two groups during followup (1 month: $P=0.515$; 3 months: $P=0.383,6$ months: $P=0.995$, respectively; Figure $2 b$ ).

\section{Time-course changes in IOP}

At 1 and 3 days postoperatively, IOP was significantly lower than that at baseline in both groups (27G: day 1 $P=0.0012$, day $3 P=0.0410 ; 25 G$ : day $1 P<0.0001$, day 3 $P=0.0350$; Figure 3a). At 7 days postoperatively, IOP recovered to the baseline value in both groups.

Three eyes in the $27 \mathrm{G}$ group and 4 in the $25 \mathrm{G}$ developed postoperative hypotony, defined as IOP of $<7 \mathrm{~mm} \mathrm{Hg}$. The IOP increased to $>10 \mathrm{~mm} \mathrm{Hg} 3$ days postoperatively in all eyes.

\section{Time-course changes in aqueous flare cell}

The mean aqueous flare cell at baseline was $5.3 \pm 1.7$ photons $/ \mathrm{ms}$ in the $27 \mathrm{G}$ group and $5.2 \pm 1.3$ photons $/ \mathrm{ms}$ in the $25 \mathrm{G}$ group (Figure $3 \mathrm{~b}$ ). There was no significant difference between them during follow-up (all $P>0.05$ ). In the $27 \mathrm{G}$ group, postoperative aqueous flare cell recovered to the baseline value at 90 days. However, there was still a statistically significant difference compared with baseline in the 25G group 180 days postoperatively.

\section{Comparison of SIA}

The mean SIA at 1,3 , and 6 months after surgery was $0.52 \pm 0.53,0.44 \pm 0.44$, and $0.29 \pm 0.37 \mathrm{D}$, respectively, in the $27 \mathrm{G}$ group. In the $25 \mathrm{G}$ group, the mean SIA at 1,3 , and 6 months after surgery was $0.56 \pm 0.47,0.45 \pm 0.38$, and $0.39 \pm 0.38 \mathrm{D}$, respectively. There was no significant difference in SIA between the two groups postoperatively (1 month: $P=0.47 ; 3$ months: $P=0.93 ; 6$ months: $P=0.77$ ).

\section{Scleral wound closure}

All sclectomies were detected by AS-OCT at each time visit. There was no significant difference between the two groups in the percentage of wound closure (Figure $4 \mathrm{a}$ ), among the three sclerotomies, or between $27 \mathrm{G}$ and $25 \mathrm{G}$ 
a
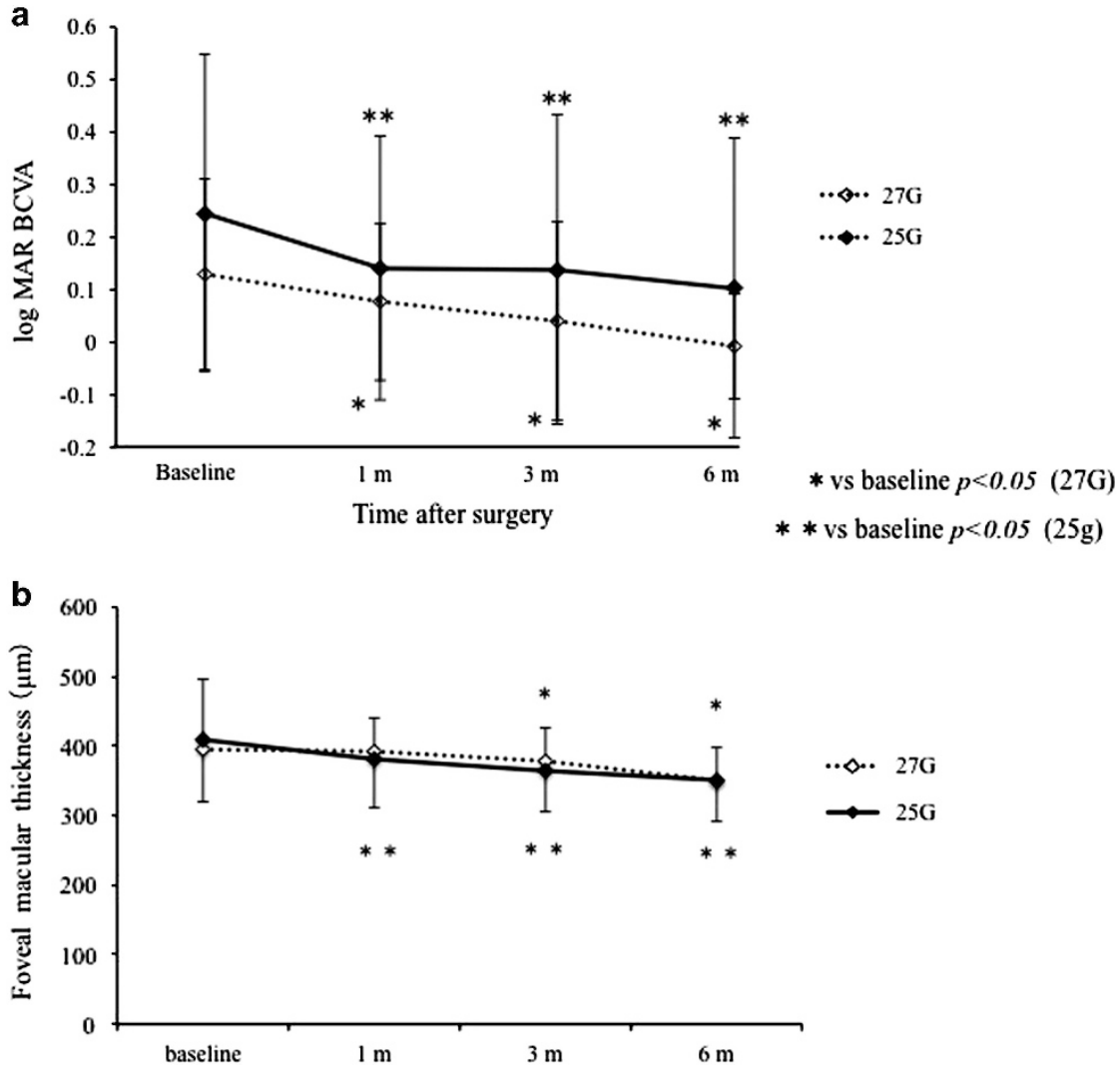

Figure 2 (a) Graph shows the time course of $\log$ MAR BCVA. The mean logMAR BCVA at baseline and 1, 3, and 6 months postoperatively was $0.13 \pm 0.18,0.08 \pm 0.15,0.04 \pm 0.19$, and $-0.01 \pm 0.10$, respectively, in the $27 \mathrm{G}$ group, and $0.26 \pm 0.30,0.16 \pm 0.25$, $0.15 \pm 0.30$, and $0.11 \pm 0.29$, respectively, in the $25 \mathrm{G}$ group. BCVA, best-corrected visual acuity; logMAR, logarithm of the minimal angle of resolution. (b) Graph shows the time course of FMT. The mean FMT at baseline and at 1, 3, and 6 months postoperatively was $397.2 \pm 98.1,396.4 \pm 47.7,382.8 \pm 49.3$, and $352.5 \pm 76.7 \mu \mathrm{m}$, respectively, in the $27 \mathrm{G}$ group and $413.2 \pm 84.3,386.6 \pm 69.3,370.5 \pm 52.6$, and $372 \pm 76.7 \mu \mathrm{m}$, respectively, in the $25 \mathrm{G}$ group. FMT, foveal macular thickness.

incisions in terms of the time required for wound closure (Figure $4 \mathrm{~b}$ ). The mean time for wound closure in the $27 \mathrm{G}$ group was $7.7 \pm 4.7$ weeks (right/cutter port: $7.9 \pm 4.2$, light port: $7.3 \pm 4.9$, and infusion port: $7.9 \pm 5.1$ weeks) and that in the 25G group was $8.6 \pm 4.6$ weeks (right/cutter port: $9.0 \pm 4.9$, light port: $8.2 \pm 4.1$, and infusion port: $8.7 \pm 4.7$ weeks).

\section{Discussion}

The results of the current study showed that both $27 \mathrm{G}$ and 25G TSV are equally effective, safe techniques for ERM surgery, as previously reported. ${ }^{11}$ To the best of our knowledge, this is the first randomized, prospective study comparing the efficacy of the two systems in the treatment of ERM. There were no significant differences in $\log$ MAR BCVA and FMT between the two groups during follow-up. It was previously reported that 25G TSV contributes to earlier visual recovery compared with 20G vitrecotmy. ${ }^{12-14}$ Our results showed that both the
$27 \mathrm{G}$ and $25 \mathrm{G}$ groups experienced a similar process of visual recovery. Taken together, it is likely to be that $27 \mathrm{G}$ TSV offers the same advantages as 25G TSV in terms of postoperative visual recovery.

The transient changes in cornea shape after pars plana vitrectomy may be due to scleral suture. MIVS allows for sutureless wounds and less wound leakage. It was reported that SIA after $23 \mathrm{G}^{15}$ and $25 \mathrm{G}$ vitrectomy ${ }^{4,16}$ was significantly less than that after 20G vitrectomy. A 25G TSV does not induce regular or irregular corneal astigmatism. ${ }^{4}$ There was no significant difference in the degree of SIA between the two groups during the postoperative follow-up period in the present study. We anticipated less SIA with the use of the $27 \mathrm{G}$ than with the $25 \mathrm{G}$ system, although that was not the case. This suggests that 27G TSV offers the same advantages as 25G TSV in terms of SIA.

There was no significant difference in the operation time for ERM-ILM peeling, irrespective of gauge.

However, vitrectomy operation time was significantly 

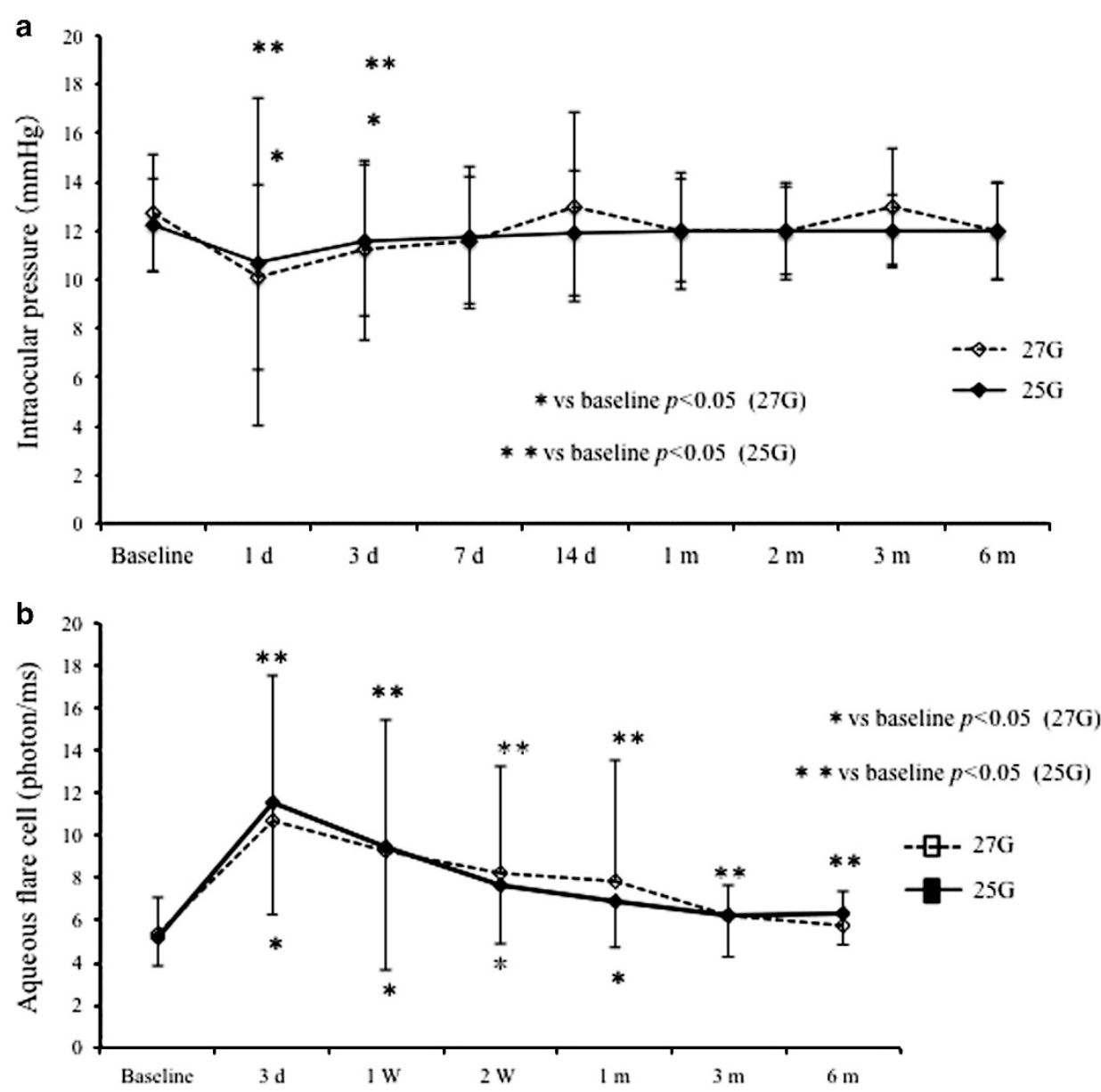

Figure 3 (a) Graph shows the time course of IOP. The mean IOP at baseline was $12.7 \pm 2.4 \mathrm{~mm} \mathrm{Hg}$ in the $27 \mathrm{G}$ group and $12.2 \pm 1.9 \mathrm{~mm} \mathrm{Hg}$ in the $25 \mathrm{G}$ group. At $1,3,7,14,30,60,90$, and 120 days postoperatively, the IOP was 10.1 $\pm 3.8,11.2 \pm 3.7,11.6 \pm 2.6$, $13.0 \pm 3.9,12.0 \pm 2.1,12.0 \pm 1.8,13.0 \pm 2.4$, and $12.0 \pm 2.0 \mathrm{~mm} \mathrm{Hg}$, respectively, in the $27 \mathrm{G}$ group, and 10.7 $\pm 6.7,11.6 \pm 3.1,11.7 \pm 2.9$, $11.9 \pm 2.6,12.0 \pm 2.4,12.0 \pm 2.0,12.0 \pm 1.5$, and $12.0 \pm 2.0 \mathrm{~mm} \mathrm{Hg}$, respectively, in the $25 \mathrm{G}$ group. None of the differences in the IOP between the two groups was significant during follow-up (day 1: $P=0.94$, day 3: $P=0.28$, day 7: $P=0.85$, day $14: P=0.57$, day 30: $P=0.76$, day 90: $P=0.43$, day 120: $P=0.65$ ). IOP, intraocular pressure. (b) Graph shows the time course of aqueous flare cell. The mean aqueous flare cell at $3,7,14,30,90$, and 180 days postoperatively were $10.6 \pm 6.8,9.3 \pm 6.1,8.2 \pm 5.1,7.8 \pm 5.4,6.2 \pm 1.5$, and $5.8 \pm 1.5$ photons $/ \mathrm{ms}$ in the $27 \mathrm{G}$ group, and 11.6 $\pm 5.2,9.5 \pm 7.2,7.7 \pm 4.1,6.9 \pm 2.0,6.2 \pm 1.8$, and $6.4 \pm 1.4$ photons $/ \mathrm{ms}$ in the $25 \mathrm{G}$ group. There was no significant difference between the two groups (27G vs 25G: $P=0.29, P=0.94, P=0.99, P=0.92, P=0.78$, and $P=0.16$, respectively).

longer in the $27 \mathrm{G}$ group due to the substantially lower infusion and aspiration rates of the vitrectomy system used in the present study. ${ }^{8}$ In addition, it could be due to distinct surgical systems but not distinct instrument gauges.

A newly developed 27G vitreous cutter with higher cutting and aspiration rates became commercially available during the course of this study. Further investigation is necessary to determine whether the new system shows better or the same efficacy as the 25G cutter in ERM surgery.

It is known that surgical trauma to the eye induces blood-aqueous barrier breakdown, leading to augmented protein leakage and cellular reactions in the aqueous humor. ${ }^{17}$ The number of combined cataract surgery was not different between the two groups (Table 1). Operation time in the $27 \mathrm{G}$ group was significantly longer than in the
$25 \mathrm{G}$ group, which might cause an increase in aqueous flare. However, in this study there was no significant difference in the aqueous flare cell between the two groups (Figure $3 b$ ). Although postoperative aqueous flare cell in the $27 \mathrm{G}$ group recovered to the baseline value 90 days postoperatively, those in the $25 \mathrm{G}$ group did not, even 180 days postoperatively. Hoshi et al ${ }^{18}$ reported that aqueous flare intensity after vitrectomy for rhegmatogenous retinal detachment decreased to a stable level 3 months postoperatively but remained significantly higher than the normal level even after 12 months. These results suggest that $27 \mathrm{G}$ vitrectomy for ERM causes less surgical trauma to the eye than $25 \mathrm{G}$ vitrectomy; however, a significant difference was not seen between the two groups. 
a

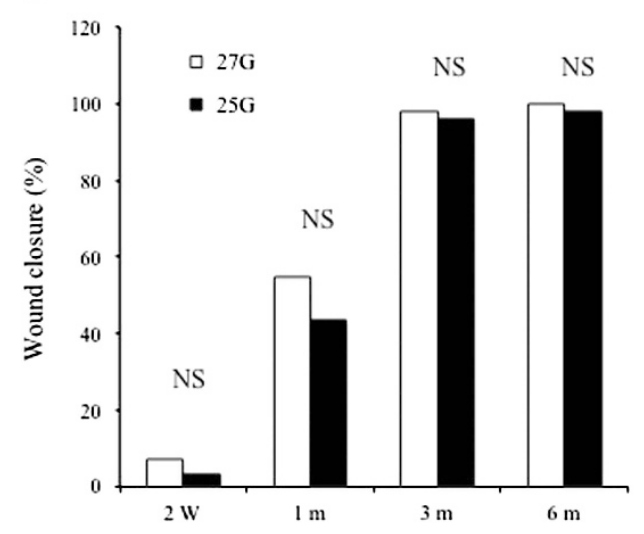

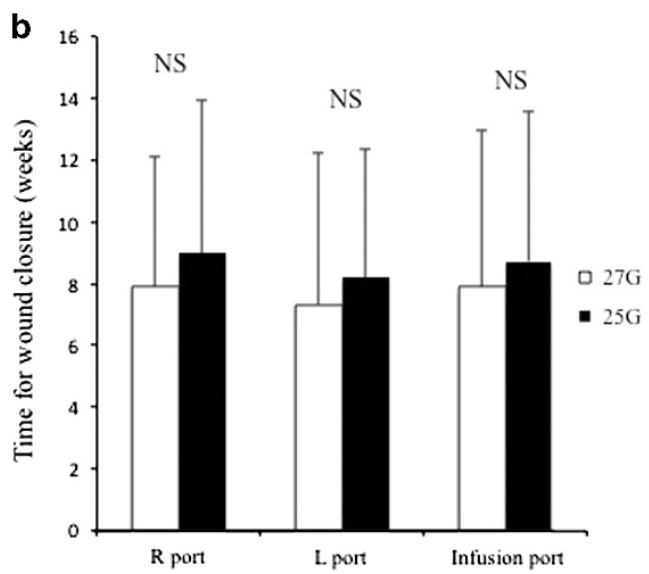

Figure 4 (a) Percentage of wound closure of all eyes. The percentages were $7.4 \%$ at 2 weeks, $54.6 \%$ at 1 month, $98.1 \%$ at 3 months, and $100 \%$ at 6 months postoperatively in the 27G group, and 3.0,43.4, 96.0, and 98.0\%, respectively, in the 25G group. (b) Time required for wound closure of the three sclerotomies. There was no significant difference between the two groups during follow-up (all $P>0.05$ ).

Postoperative hypotony is reported in $0-25 \%$ of sutureless vitrectomy cases. ${ }^{19,20}$ Hypotony is usually transient and, in most cases, resolves with conservative measures. There were 3 cases of hypotony in the $27 \mathrm{G}$ group and 4 in the 25G group (Figure 3a). None of the differences in the IOP between the two groups was significant at any follow-up visit and the IOP recovered to $>10 \mathrm{~mm} \mathrm{Hg}$ in all eyes 3 days postoperatively. Oshima et $a l^{8}$ reported that the overall mean IOP before and after surgery when using the $27 \mathrm{G}$ system was stable with no significant differences among the examination time points (postoperative days 1, 7, and 30). However, they used long-acting gas or air tamponade in some cases. The mean postoperative day 1 IOP in eyes without gas tamponade use was lower than that in eyes with it. In addition, Yamane $e a^{21}$ found that the IOP was significantly higher in gas-filled eyes than in fluid-filled eyes on postoperative day 1 after 25G TSV. In the present study, we did not use gas tamponade, which may explain the difference in the postoperative IOP between the two studies.

We speculated that $27 \mathrm{G}$ incisions would seal more easily than $25 \mathrm{G}$ ones. However, the mean time for scleral wound closure did not differ significantly between the two groups at any time point. The mean time required for scleral wound closure in the $27 \mathrm{G}$ group was $7.7 \pm 4.7$ weeks, and that in the $25 \mathrm{G}$ group was $8.6 \pm 4.6$ weeks. Although we assumed that the smaller incision size would decrease the time required for woundhealing, there was no significant difference between the two groups. It appears that this result is due to surgical invasion of the scleral wound. The $27 \mathrm{G}$ vitreous cutter and forceps had to be moved more dynamically when shaving the peripheral vitreous and peeling the ERM, because the cutter of $27 \mathrm{G}$ systems is shorter and weaker than the 25G cutter. However, there was no significant difference among the three sclerotomy sites (right port, left port, and infusion port; Figure $4 \mathrm{~b}$ ). If the incision size affects wound closure time, the time required for the right port (the side of the surgeon's dominant hand) should be longer than that for the other ports.

In this study, the trocar was placed at a $30^{\circ}$ oblique angle to the scleral surface. Angled incisions can help prevent wound leakage by allowing the internal lip to press against the outer lip through IOP, thereby closing the wound. ${ }^{2}$ However, significant manipulation of the sclerotomies due to the movement of instruments in awkward and extreme directions/positions during vitrectomy and membrane peeling can change the wound architecture from its original construction, making the wound relatively unstable and unpredictable. ${ }^{22}$ To confirm whether an oblique or vertical incision is better for wound sealing when using the $27 \mathrm{G}$ system, we are now conducting a new study.

\section{Study limitations}

There are potential limitations in this study. First, the insertion angle of the trocar was not measured during scleral penetration. Thus, there may have been some variations in the angle. To minimize these variations, all sclerotomies were performed by a single surgeon. Second, the relatively small sample size in our study is insufficient for a noninferiority study. Third, it is true that there may be substantial differences between the two MIVS systems (accurus vs constellation). In addition, it may be that this study was the only comparative clinical outcome but not the surgical one. However, our pilot study will be helpful in planning and conducting further larger-scale prospective studies. Similar to the recent evolution in $23 \mathrm{G}$ and 25G systems, further development and refinement of the functions of the $27 \mathrm{G}$ instrument are required. 
In conclusion, 27G TSV results in similar clinical outcomes to 25G TSV. We performed comparative prospective study and demonstrated that feasibility, preliminary safety, and low complication rate of 27G MIVS systems are equivalent to those of 25G MIVS systems.

\section{Summary}

What was known before

- None.

What this study adds

- Feasibility, preliminary safety, and low complication rate of $27 \mathrm{G}$ vitrectomy.

\section{Conflict of interest}

The authors declare no conflict of interest.

\section{References}

1 Fuji GY, De Juan Jr E, Humayun MS, Pieramici DJ, Chang TS, Awh C et al. A new 25-gauge instrument system for transconjunctival sutureless vitrectomy surgery. Ophthalmology 2002; 109: 1807-1812.

2 Eckardt C. Transconjunctival sutureless 23-gauge vitrectomy. Retina 2005; 25: 208-211.

3 Rizzo S, Genovesi-Ebert F, Murri S, Belting C, Vento A, Cresti $\mathrm{F}$ et al. 25-Gauge, sutureless vitrectomy and standard 20-gauge pars plana vitrectomy in idiopathic epiretinal membrane surgery: a comparative pilot study. Graefes Arch Clin Exp Ophthalmol 2006; 244: 472-479.

4 Okamoto F, Okamoto C, Sakata N, Hiratsuka K, Yamane N, Hiraoka $\mathrm{T}$ et al. Changes in corneal topography after 25 -gauge transconjunctival sutureless vitrectomy versus after 20-gauge standard vitrectomy. Ophthalmology 2007; 114 2138-2141.

5 Misra A, Ho-Yen G, Burton RL. 23-gauge sutureless vitrectomy and 20-gauge vitrectomy: a case series comparison. Eye (Lond) 2009; 23: 1187-1191.

6 Kellner L, Wimpissinger B, Stolba U, Brannath W, Binder S 25-gauge vs 20-gauge system for pars plana vitrectomy: a prospective randomised clinical trial. Br J Ophthalmol 2007; 91: 945-948.

7 Patelli F, Radice P, Zumbo G, Frisone G, Fasolino G. 25-gauge macular surgery: results and complications. Retina 2007; 27: 750-754.

8 Oshima Y, Wakabayashi T, Sato T, Ohji M, Tano Y. A 27-gauge instrument system for transconjunctival sutureless microincision vitrectomy surgery. Ophthalmology 2010; 117: 93-102.

9 Chen JC. Sutureless pars plana vitrectomy through selfsealing sclerotomies. Arch Ophthalmol 1996; 114: 1273-1275.

10 Holladay JT, Cravy TV, Koch DD. Calculating the surgical induced refractive change following ocular surgery. J Cataract Refract Surg 1992; 18: 429-443.

11 Sandali O, El Sanharawi M, Lecuen N, Barale PO, Bonnel S, Basli E et al. 25-, 23-, and 20-gauge vitrectomy in epiretinal membrane surgery: a comparative study of 553 cases. Graefes Arch Clin Exp Ophthalmol 2011; 249: 1811-1819.

12 Yoon YH, Kim DS, Kim JG, Hwang JU. Sutureless vitreoretinal surgery using a new 25- gauge transconjunctival system. Ophthalmic Surg Lasers Imaging 2006; 37: 12-19.

13 Rizzo S, Genovesi-Ebert F, Murri S, Belting C, Vento A, Cresti $\mathrm{F}$ et al. 25-gauge, sutureless vitrectomy and standard 20-gauge pars plana vitrectomy in idiopathic epiretinal membrane surgery: a comparative pilot study. Graefes Arch Clin Exp Ophthalmol 2006; 244: 472-479.

14 Kadonosono K, Yamakawa T, Uchio E, Yanagi Y, Tamaki Y, Araie M. Comparison of visual function after epiretinal membrane removal by 20 -gauge and 25-gauge vitrectomy. Am J Ophthalmol 2006; 142: 513-515.

15 Park DH, Shin JP, Kim SY. Surgically induced astigmatism in combined phacoemulsification and vitrectomy: 23-gauge transconjunctival sutureless vitrectomy versus 20-gauge standard vitrectomy. Graefes Arch Clin Exp Ophthalmol 2009; 247: 1331-1337.

16 Galway G, Drury B, Cronin BG, Bourke RD. A comparison of induced astigmatism in 20- vs 25-gauge vitrectomy procedures. Eye (Lond) 2010; 24: 315-317.

17 Nishino M, Eguchi H, Iwata A, Shiota H, Tanaka M, Tanaka T. Are topical steroids essential after an uneventful cataract surgery? J Med Invest 2009; 56: 11-15.

18 Hoshi S, Okamoto F, Hasegawa Y, Sugiura Y, Okamoto Y, Hiraoka $\mathrm{T}$ et al. Time course of changes in aqueous flare intensity after vitrectomy for rhegmatogenous retinal detachment. Retina 2012; 32: 1862-1867.

19 Teixeira A, Allemann N, Yamada AC, Uno F, Maia A, Bonomo PP. Ultrasound biomicroscopy in recently postoperative 23-gauge transconjunctival vitrectomy sutureless self-sealing sclerotomy. Retina 2009; 29: 1305-1309.

20 Scott IU, Flynn Jr HW, Dev S, Shaikh S, Mittra RA, Arevalo JF et al. Endophthalmitis after 25-gauge and 20-gauge pars plana vitrectomy: incidence and outcomes. Retina 2008; 28: 138-142.

21 Yamane S, Kadonosono K, Inoue M, Kobayashi S, Watanabe Y, Arakawa A. Effect of intravitreal gas tamponade for sutureless vitrectomy wounds: three-dimensional corneal and anterior segment optical coherence tomography study. Retina 2011; 31: 702-706.

22 Taban M, Ventura AA, Sharma S, Kaiser PK. Dynamic evaluation of sutureless vitrectomy wounds: an optical coherence tomography and histopathology study. Ophthalmology 2008; 115: 2221-2228.

This work is licensed under a Creative Commons Attribution-NonCommercialNoDerivs 4.0 International License. The images or other third party material in this article are included in the article's Creative Commons license, unless indicated otherwise in the credit line; if the material is not included under the Creative Commons license, users will need to obtain permission from the license holder to reproduce the material. To view a copy of this license, visit http://creativecommons.org/licenses/by-nc-nd/4.0/ 